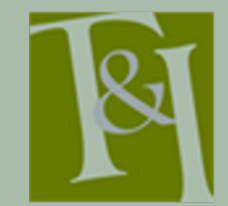

The International Journal for Translation \& Interpreting Research trans-int.org

\title{
Yes! We're open. Open science and the future of academic practices in translation and interpreting studies
}

\author{
Christian Olalla-Soler \\ MC2 Lab, Università di Bologna, Italy \\ christian.olalla@unibo.it
}

DOI: $10.12807 /$ ti.113202.2021.a01

\begin{abstract}
This article offers an overview of open science and open-science practices and their applications to translation and interpreting studies (TIS). Publications on open science in different disciplines were reviewed in order to define open science, identify academic publishing practices emerging from the core features of open science, and discuss the limitations of such practices in the humanities and the social sciences. The compiled information was then contextualised within TIS academic publishing practices based on bibliographic and bibliometric data. The results helped to identify what open-science practices have been adopted in TIS, what problems emerge from applying some of these practices, and in what ways such practices could be fostered in our discipline. This article aims to foster a debate on the future of TIS publishing and the role that open science will play in the discipline in the upcoming years.
\end{abstract}

Keywords: Open science; academic publishing; translation and interpreting studies; bibliometrics.

\section{Introduction}

Almost thirty years ago, open science and its practices began to unfold in many disciplines at different paces (Bartling \& Friesike, 2014). While the core set of underlying principles of open science are arguably applicable to all disciplines, most were geared toward science, technology, engineering, and mathematics, the so-called STEM disciplines. Hence, open-science practices may have been adopted to various degrees in different disciplines. In translation and interpreting studies (TIS), open access seems to be the most visible one.

The aims of this article are: (1) to provide a global overview of open science and its practices; and (2) to describe open-science practices in TIS. To do so, the following questions will be answered:

1. What is open science?

2. What practices arise from open science? What are their benefits and drawbacks?

3. Are open-science practices applicable to TIS? What has been done until now? What problems are we facing?

4. How can open-science practices be fostered in TIS?

Questions 1 and 2 entailed a literature review of publications dealing with the development of open science and its application to academic publishing practices. For questions 3 and 4, the information compiled on open science was supplemented with bibliographic and bibliometric data on TIS publishing practices, mainly retrieved from the Bibliography of Interpreting and 
Translation (BITRA; Franco Aixelá, 2001-2021) and Translation Studies Journals (RETI; Biblioteca d'Humanitats-Universitat Autònoma de Barcelona, 2013-2021).

\section{Defining open science}

Open science is not a novel concept. One of the earliest and most famous examples of open-science practices was the Human Genome Project, launched in the 1990s (Collins, Michael \& Patrinos, 2003). Sharing data on the human genome with the scientific community meant that the genome could be decoded in much less time than it would otherwise have taken if research had been compartmentalized and unconnected among competing research teams. The most remarkable fact by far is that data sharing occurred before the World Wide Web as we know it today. Indeed, one of the keys to open science is the impact of the internet and new information and communication technologies on the dissemination and sharing of scientific knowledge (Burgelman et al., 2019).

The dissemination of much of scientific information has shifted from print to online venues, especially, in the last decade. This change in dissemination practices has opened up new ways of sharing scientific knowledge (like online blogs), modified scholarly publishing practices - e.g., uploading pre- and postprints to public repositories, not capping the number of articles per journal issue for electronic-only journals, greater flexibility with word and page counts, the inclusion of supplementary materials - and provided scholars with new ways to communicate and discuss scientific advances, such as scientific social networks and crowdsourced reviewing.

Information and communication technologies have also expanded the boundaries of science by allowing scholars to perform large-scale distributed computing of scientific data. We find this in projects such as SETI@home (Korpela et al., 2001) and the IBM World Community Grid (IBM, 2004), which use grid computing to attempt to identify radio signals from extra-terrestrial intelligence in the first case and to analyse big data from natural and health science projects in the second. The ability to distribute data and incorporate new analytical techniques at a larger scale illustrates how technologies enable science to evolve in order to incorporate new research practices, and, as argued here, to revisit how findings are reported and shared.

There are plenty of definitions of open science and most of them share a core set of underlying principles: transparency, universal accessibility, communality, reusability of data, and scepticism (Pontika et al., 2015). Before providing a working definition of open science, let us examine these principles.

Transparency. Open science aims at making accessible not only scientific results (such as scholarly publications) but also the whole process followed so that peer scholars and society are able to assess the quality, validity, and reliability of scientific procedures (see Elliott \& Resnik, 2019 for a discussion on transparency in science).

Universal accessibility. Open science aims at making scientific knowledge accessible not only to other scholars but to society (see Fecher \& Friesike, 2014 for a discussion on the implications of universal accessibility for scientific communication).

Communality. Scientific results do not belong to single researchers or organisations, but to the whole scientific community and to society writ large. Thus, data and the thorough description of the methods used to collect them should be made publicly available (see Bowman \& Keene, 2018).

Reusability. Data, methods and tools can be reused by other scholars with many purposes. While some may use open data to reanalyse and check 
previously reported analyses, others may employ them to refine and expand already existing knowledge by means of meta-analyses or by combining different sets of comparable data, or to generate new hypotheses for future research (see Phillips \& Knoppers, 2019 for a discussion on legal issues on data sharing and reusability).

Scepticism. Ensuring the quality of research with detached and logical criteria is rendered easier with open-science practices. Accessible datasets and data analysis procedures are necessary to optimise scientific assessment: a result is not true simply because the authors state that it is so in their report, but rather because any other scholar can independently verify it. As expressed by Bowman \& Keene (2018, p. 364), this is a shift from "trust me, I am a scientist" to "here, let me show you".

The working definition of open science in this article is based on the principles above and combines Pontika et al. $(2015$, p. 1) with that of the National Academies of Sciences, Engineering, and Medicine (NAS 2018, p. 1):

Open science is a set of scholarly practices aiming to make scientific knowledge and the means to achieve it universally accessible. To do so, it fosters scientific transparency and reusability of data by taking advantage of the potential of information and communication technologies.

One may wonder whether the concept of open science was tailored for STEM disciplines and that, once again, the humanities and the social sciences had been overlooked. This seems to be partly so. Open science was born in STEM disciplines and the shaping of the concept directly derived from the specific scholarly publishing practices of these disciplines (Sidler, 2014). However, several open-science practices are also applicable to a greater or lesser extent in TIS.

\subsection{Open-science practices}

\subsubsection{Open access}

One of the most widely adopted understandings of open access (OA) is based on the Budapest Open Access Initiative Declaration (BOAI, 2002). Here, OA is conceived as the free and universal access to peer-reviewed literature. The traditional focus of OA has been on journal articles, as this was the conventional publication format in STEM disciplines. More recently, many scholars have started discussing the role e-books will play in the development of OA in the case of the humanities and the social sciences (Sitek \& Bertelmann, 2014), where scholarly book publishing is more frequent, given that publishing ebooks reduces costs and circulation is larger than in the case of hard copies.

With the advent of the internet, we see OA emerge as new digital opportunities are applied to the problems of the legacy hardcopy publishing system of the time. Some authors argue that scientific journals, which appeared in the $17^{\text {th }}$ century, and scholarly publishing practices have remained almost unaltered until the internet era (see for instance Nosek \& Bar-Anan, 2012). A closer examination of the history of scientific journals suggests otherwise. We need to distinguish between learned journals, i.e., journals edited by learned societies, and commercial journals (Fyfe, 2016). Already in the $18^{\text {th }}$ century, most scientific journals were commercial, but their lifespan was rather short and, in any case, shorter than that of learned journals (Fyfe, 2016). What these two types of journals shared was their lack of profitability, at least until the $20^{\text {th }}$ century (see Fyfe, 2015 for a study of Philosophical Transactions as a case in point). The causes, however, had different origins. According to Fyfe (2016), learned journals were generally conceived to be not-for-profit, as they were distributed mainly for free to the fellows of a society or were given as a gift to other societies. These journals did not have a fixed number of pages, which 
made the price of each issue vary. As the reputation of learned journals increased, so too did the page count per issue and, consequently, their cost. Learned journals became more specialised over time, thereby decreasing or narrowing their potential readership. In origin, commercial journals targeted a different audience, as they were not venues where the newest research was presented. In some cases, these were journals for laypeople (Bowler, 2009) and, in others, they offered a type of content based on reviews, pieces of news, and letters that might be of interest for scholars but were difficult to access due to limited circulation of learned journals. Commercial journals were not the main way to be informed about the latest advances in a discipline for scholars, and the general interest for science by laypeople did not increase until the $19^{\text {th }}$ and $20^{\text {th }}$ century (Bowler, 2009). Commercial and learned journals were not profitable (or at least sustainable) until the $20^{\text {th }}$ century, when the difference between the two types became blurred as a new journal type appeared (journals endorsed by learned societies and published by commercial publishers) and a progressive standardisation of format and style occurred (Atkinson, 1998).

The origin of peer review is to be found in journals published by learned societies in the $18^{\text {th }}$ and $19^{\text {th }}$ centuries, in which a committee took collective decisions on the merits for publication of submitted papers (Fyfe, 2016). In some cases, these papers had to meet other requirements, such as having been presented at a meeting of the society to which the paper had been submitted for publication (Zuckerman \& Merton, 1971). Over time, learned societies developed mechanisms to control the quality of their respective journals, such as referee reports (Despeaux, 2011) or the standardisation of specific text genres (as in the journal article; see Bazerman, 1988, pp. 80-127). Fyfe (2016) estimates that the generalised use of systems such as peer review by commercial journals is roughly dated to the years after the Second World War, and stresses that it is not until the 20th century that the characteristics we observe in scientific journals today, i.e., "originality of research, self-authorship, refereeing procedures and standardized rhetoric and structure" (2016, p. 387) become apparent.

In the $20^{\text {th }}$ century, print-based dissemination of scientific knowledge was heavily influenced by the number of pages made available for a specific journal issue (Nosek \& Bar-Anan, 2012). Such a limitation of space had direct consequences that affected how and which articles were selected for publication. Hence, articles tend to present similar characteristics - in particular, statistical significance and novelty. Null results and replications are seldom published (i.e., the file-drawer problem; Nosek, Spies \& Motyl, 2012). Copyright ownership of scientific articles is transferred to publishers for free, in exchange for a set of services such as typesetting, printing and distribution (Nosek \& Bar-Anan, 2012). As Nosek and Bar-Anan put it, research has been generally produced by means of public funding and ended up in a non-public domain.

The benefits of OA are well-known and scientific communities generally hold positive views on it (Ross-Hellauer, Deppe \& Schmidt, 2017). It is also a widely adopted practice, not least because an increasing number of public funding institutions require that results from funded projects be published in OA (Pontika et al., 2015).

Two main types of OA routes (i.e., ways of making a research output publicly accessible) co-exist today: green and gold OA (Harnad et al., 2004). Green OA refers to self-archiving a pre-print or a post-print version of a publication in an OA repository. ${ }^{1}$ Gold OA refers to publishing research outputs

\footnotetext{
1 Online social networks for scientists such as Academia.edu or ResearchGate cannot be considered open-access repositories. To qualify as open access, repositories need to (a) support document export or harvesting; (2) ensure long-term preservation of documents; (c) have nonprofit business models; and (d) check that open-access policies are fulfilled when uploading documents (further discussion in Fortney \& Gonder, 2015).
} 
in venues (mainly journals) that are freely and openly accessible directly from the publisher's website.

Journals can also be classified based on their funding model (Fuchs \& Sandoval, 2013). This classification will be used when discussing TIS journals in section 3:

- $\quad$ Toll-access or subscription-based journals. Authors are not required to pay article processing charges (APCs), but individuals or institutions need to pay a subscription fee to access the published articles.

- Hybrid journals. This model is mostly present in toll-access journals in which authors pay APCs to make their text publicly accessible. Authors not willing to pay APCs can still publish, but their articles will only be accessible for subscribed individuals or institutions.

- Gold open-access journals. In STEM disciplines, these journals are generally funded by the APCs that authors must pay to make these journals economically sustainable, and all articles are publicly accessible.

- Diamond open-access journals. In the humanities and the social sciences, gold OA does not appropriately reflect the funding model of most existing OA journals. Fuchs \& Sandoval (2013) use diamond OA to describe journals where authors are not required to pay APCs and neither are institutions or individuals required to pay or subscribe to read articles.

APCs have been in use since 2002 (Appel, Albagli \& MacIel, 2018) and were widely adopted by publishers in several disciplines. Morrison (2018) observed that, in 2017, in the Directory of Open Access Journals (DOAJ), roughly one quarter $(27 \%-3,795)$ of the journals charged APCs, while $53 \%$ did not charge any publication fee. The remaining $20 \%$ were inactive, did not provide this information, or were not OA. The mean APC was $\$ 974$ (median $=$ 750 ; mode $=1,780$; standard deviation $=832$ ). Of the journals requiring APCs, $58 \%$ charged between 0 and 1,000 USD, and 31\% charged 1,000-2,000 USD. For research projects or scholars without funding grants or support, such costs could be problematic if not prohibitive. The application (or imposition) of APCs may be an economic barrier to scientific knowledge dissemination for many scholars (Eve, 2015). This situation is of particular concern in the humanities, where both research and publishing practices differ greatly from those in STEM disciplines - which, being more frequently funded than the humanities, are better suited for APC journal models (Eve, 2015). For perspective, the APCs applied by a gold OA journal may represent more than a monthly salary of a scholar working in a low-income country as classified by the World Bank (Matheka et al., 2014). Yet just a few years ago only half of publishers applying APCs waived them for authors in low- and middle-income countries (Burchardt, 2014); subsequently Morrison (2018) reports that many publishers were now applying a country-income waiver. Nonetheless, in a survey on attitudes toward open access in low- and middle-income countries with 507 respondents, Nobes and Harris (2019) found that $71 \%$ of their informants had paid APCs to publish open access in the three years before the survey was conducted. In all, $60 \%$ footed the costs themselves, $26 \%$ received funding to cover them, and only $14 \%$ received a waiver from the publisher. ${ }^{2}$

The hybrid-journal model is also problematic with regard to APCs. Authors cover the costs of the APCs (usually paid thanks to research funding) to make their article OA in a hybrid journal. At the same time, hybrid journals

\footnotetext{
${ }^{2}$ Readers are encouraged to examine figure 1 in Pan et al. (2012). It shows a citation map of the world where the area of each country has been scaled according to the number of citations received (extracted from ISI Web of Science for all disciplines). Low- and middle- income countries almost disappear.
} 
maintain their subscription models for libraries and institutions, which are not allowed to subscribe to specific articles only (i.e., those not in OA), but must instead pay a full-access subscription fee, usually per volume or per issue (Sitek $\&$ Bertelmann, 2014). As a result, some institutions pay twice for free access to the same article: firstly, by funding the authors' APCs and, secondly, through subscriptions. In response, in 2018 cOALition S, a group of research funding organisations with the support of the European Commission and the European Research Council, launched Plan S, an initiative that aims at implementing all necessary measures so that (cOALition S 2018, para. 1):

with effect from 2021, all scholarly publications on the results from research funded by public or private grants provided by national, regional and international research councils and funding bodies, must be published in Open Access Journals, on Open Access Platforms, or made immediately available through Open Access Repositories without embargo.

To that end, funders adhering to Plan S will stop financial support for "hybrid" publication fees in subscription venues and will only fund publishing in (gold or diamond) OA venues. Plan S, however, might have an unintended negative effect. Given the struggles of diamond journals to remain financially sustainable (Bosman et al., 2021), and since most of their contributing authors are based in middle- and high- income countries where funding of APCs is (more) likely, some may be tempted to transition to a gold OA model ${ }^{3}$. This 'title flight' would reduce the list of journals to which authors from lower- and middle-income countries may be able to submit their papers. ${ }^{4}$

\subsubsection{Open data}

Open data aims at making the data employed for a study publicly available. Data is here understood not only as raw data, but also as the code generated to analyse the data. Generally, open data is associated with publication in venues that allow the addition of supplementary materials; otherwise, it is uploaded to public repositories and a link is offered in the publication (Kidwell et al., 2016).

Data sharing allows researchers to reuse data from other scholars, mainly for two purposes (West, 2016): checking for and correcting errors, and performing additional analyses. Open data aims at fostering replication, a step of the scientific method that has been a matter of concern in recent years because of the low number of replications performed and the low replicability of science, especially in social sciences (Baker \& Penny, 2016). The applicability of this open-science practice in the humanities is generally low, since empirical data it is not as prevalent as in the social sciences and STEM disciplines.

Open data poses many challenges, but two stand out from the rest. The first is researcher-specific challenges. Making data public is a way of exposing oneself to possible criticism (but also to possible praise). Such criticism may arise when other researchers fail to verify published results and the researchers' credibility is questioned. This leads to a paradox raised by Ioannidis (2016): those who adhere to best scientific practices and wish to be transparent are the ones who are most exposed to criticism and scrutiny from other researchers, while the ones who choose not to release their data are left in a limbo where their results and claims cannot be verified by others.

\footnotetext{
${ }^{3}$ Hybrid journals might also find this option economically interesting given that all authors would pay APCs. cOALition S (2021) is drafting "transformative agreements" to convert hybrid and subscription-based journals to "transformative journals", i.e., gold open-access journals.

${ }^{4}$ According to the 2020 edition of the World Bank classification of countries by income, 22 (88\%) of the headquarters out of the 24 organisations adopting Plan S in 2020 are located in high-income countries, $2(8 \%)$ in upper middle-income countries, and $1(4 \%)$ in lower middle-income countries. This does not mean, of course, that scholars from countries other than those where some of these organisations are located are not eligible to apply for research funding.
} 
The second challenge is institutional-specific challenges, mainly related to legal and ethical constraints. Data that is gathered from at-risk populations or could lead to identifying informants is extremely sensitive and, in many cases, cannot be made available without compromising the participants' anonymity. Privacy laws and regulations tend to limit the use of personal data to the original purpose, i.e., the one for which the individual's informed consent was given. As a consequence, future and unforeseen uses of data are generally ruled out. Thus, researchers need to find a (not so easy) balance between making accessible as much data as possible and taking due care of the participants' privacy rights (cf. Phillips \& Knoppers, 2019 for a discussion on the balance between data sharing and legal constraints in the European Union).

\subsubsection{Open methods and tools}

Open methods and tools are generally described as the bridge between preprocessed data and the resulting research output (Kraker et al., 2011). 'Open tools' means making all tools in a study accessible, both to gather and to analyse data. 'Open methods' refers to a detailed description of the methodological process followed in a study. These complete and detailed descriptions are seldom found in scientific venues, especially in those limited by page or word counts (Pontika et al., 2015).

Open methods and tools are closely related to pre-registration, a public date/time-stamped declaration of the research goals, hypotheses, design, sampling procedure and data analysis plans lodged prior to conducting the study. The benefits of pre-registration are many (Nosek et al., 2018): it allows distinguishing between exploratory (hypothesis-generating research) and confirmatory research (hypothesis-testing research). It also increases transparency, since scholars reviewing publications derived from a preregistered study can identify deviations from the pre-registered plans and the motivation for such changes, and it serves as guidance for other researchers who can look for methodological descriptions of procedures they can apply in their research.

However, pre-registration has not been applied evenly across disciplines. In some disciplines in some countries - e.g. government-funded clinical research in the United States - it is a legally established requirement (Miguel et al., 2014). In health-related disciplines, pre-registrations may even be a requisite to submit manuscripts to journals (such as Comprehensive Results in Social Psychology or The Journal of Politics, which both only accept articles reporting on pre-registered research). Funding sources, such as the Pre-registered Research Grants of the European Association of Social Psychology, may also require pre-registration. While in some disciplines and countries preregistration is not only desired but required, in others only a few examples of pre-registered studies may be found (Nosek et al., 2018). Again, this is the case in the humanities and in some social-science disciplines. Pre-registration has been criticised because it may prevent spontaneous scientific discoveries typical of exploratory research (Leavitt, 2013). However, pre-registration does not reject exploratory research per se, but allows the clear identification and disclosure of hypothesis-testing and hypothesis-generating research.

\subsubsection{Open peer-review}

Open peer-review has attracted much attention in the open-science movement. The need to introduce more transparent peer-review practices springs from: (1) publication and social biases affecting traditional, double-blind peer-review, such as gender, language, nationality, and institutional affiliation to name but a few (see Ross-Hellauer, Deppe \& Schmidt, 2017); (2) the limitations of doubleblind peer-review, such as the limited rate of errors that reviewers can detect in a manuscript (Bakker \& Wicherts, 2011); lack of transparency that may foster unethical peer-review practices, such as acting in one's own interest by hiding 
conflicts of interest; stealing ideas; intentionally blocking or delaying publication of competitors' ideas, and favouring friends and targeting enemies (Smith, 2006); and (3) the scarce incentives to act as a reviewer and produce a good review both in terms of academic rewards - peer-review is anonymous, so researchers cannot be credited for their reviews (Ware, 2008) - and economic rewards: although peer-review is practically unpaid, ${ }^{5}$ in 2008 Research Information Network estimated that the value of volunteer peer-review was more than 3 billion USD globally (RIN, 2008). ${ }^{6}$ Fortunately, a great number of reviewers keep providing high-quality reviews despite this lack of compensation and recognition. Thanks to them we are standing on firmer ground.

Open peer-review has been understood in many ways. Ross-Hellauer (2017) analysed 122 definitions and identified seven traits that could be combined to yield 22 type classifications of OA peer review. In an attempt to reach a comprehensive definition, the author proposed the following (RossHellauer 2017, p. 604):

Open peer review is an umbrella term for a number of overlapping ways that peer review models can be adapted in line with the aims of Open Science, including making reviewer and author identities open, publishing review reports and enabling greater participation in the peer review process.

The 22 combinations were based on the following seven traits (RossHellauer 2017, p. 604):

1. Open identities. Both the authors and the reviewers know each other's identity.

2. Open reports. The review reports are published jointly with the reviewed article.

3. Open participation. The scientific community is able to contribute to the review process at a pre- or post-peer-review stage.

4. Open interaction. Authors are able to engage in a discussion with reviewers. Reviewers are also allowed to interact between them and discuss the manuscript.

5. Pre-review manuscripts. Manuscripts are made available (e.g., in OA repositories) before any peer-review procedure takes place.

6. Open final-version commenting. The scientific community and the authors are able to comment on the final version of a publication.

7. Open platforms (decoupled review). The review is not carried out by the venue of publication but by a different organisation that focuses on facilitating review processes, such as RUBRIQ and Peerage of Science.

In Ross-Hellauer's (2017) review of 122 definitions, open identities and open reports were both included in $116(95.1 \%)$ definitions. Combining these two traits with open participation covered 121 definitions (99.2\%). Hence, these are the core traits of open peer-review: open identities, open reports, and open participation. Let us discuss them in greater detail.

Blind peer-review has proven to be sensitive to bias, as presented above. In small (sub-) disciplines, reviewers are often able to guess who the authors are based on the topic of their publication or the methodology (Godlee, Gale \& Martyn, 1998). Godlee, Gale \& Martyn (1998) note that neither open nor

\footnotetext{
${ }^{5}$ This may vary by discipline. In TIS, reviews of book proposals and full-length manuscripts are frequently remunerated.

${ }^{6}$ A recently launched web service, Publons, aims at providing academic credit to reviewers. While it is still a free service, it is owned by a for-profit company and it is not aligned with the principles of open science.
} 
blinded identities increased the quality of the reviews. So, what benefits then do open identities offer? According to Ross-Hellauer (2017), these are accountability, credit for reviewers and fairness. Open identities can provide a way to identify biases and to prevent reviewers from employing unethical practices, such as undisclosed conflicts of interest. ${ }^{7}$

Open reports boost the benefits of open identities (van Rooyen, Delamothe \& Evans, 2010) even if in some cases the reports may be published without the reviewers' names. They may also be an interesting resource for (younger) researchers, who can use good-quality open reviews (despite the difficulty of determining what a good-quality review is) as models for their own reports. In this regard, it should be mentioned that there is also scant literature on the benefits of training in peer review ${ }^{8}$ both in general and within TIS (see for instance Gambier et al., 2019, for a discussion on the competences that should be addressed in doctoral training in our discipline). The existing literature, besides being scarce, has provided contradictory results on such benefits. To illustrate this, Freda et al. (2009) observed a positive effect of reviewer training in nursing research, while Houry et al. (2012) did not observe a change in the quality of reviews of new reviewers who had participated in a mentoring programme in the field of medical research.

In open participation or crowd-sourced peer-review, editors invite members of the scientific community who might be interested in a specific topic to act as reviewers by providing full reports or short comments. Open participation aims at improving the reliability of peer-review by increasing the number of reviewers. This procedure faces some challenges. The first one is technical: many publishing platforms do not allow open participation, so publishers would need to bear the costs of implementing it. The second challenge is finding the right scholars to participate in a crowd-sourced peerreview. Monitoring scholars offering negative, inaccurate and provocative comments (i.e., "trolls"; Nosek \& Bar-Anan, 2012) may become difficult and time-consuming.

A third challenge is the acceptance of open peer-review by the scientific community. The implementation rate of open peer-review varies widely from one discipline to the other. In the humanities, the numbers for journals implementing some type of open peer-review are uncertain while the practice is reported to be rather infrequent in social sciences (Wolfram et al., 2020). Open peer-review practices may deter authors and reviewers from publishing in and reviewing for venues that use them: scholars feel that reviewers should be allowed to decide whether or not their identities are open (Ross-Hellauer, Deppe $\&$ Schmidt, 2017). Hence, applying open peer-review calls for a change in scholars' attitudes. In fact, most of the journals in the humanities and the social sciences that implemented open reports or open identities did it on an optional basis for their authors and reviewers $(71.4 \%$ and $60 \%$ respectively; Wolfram et al., 2020). Ross-Hellauer and Görögh (2019) offer some guidelines to editors willing to implement open peer-review practices. Such guidelines may help to progressively modify both authors' and reviewers' attitudes toward this openscience practice.

\subsubsection{Open research evaluation}

Applying open practices to science has a direct impact on research and on researcher evaluation. Open science entails expanding research outputs to data, methods, tools, pre-registrations, review reports, and the like. Evaluation metrics need to be adapted to the resulting practices in academic publishing. Metrics primarily (or exclusively) based on journal publications are less relevant in this new context, and so are journal-level metrics - such as the

7 COPE's (2013) Ethical guidelines for peer reviewers classifies conflicts of interest into personal, financial, intellectual, professional, political, and religious.

${ }^{8}$ See Khoo (2018) for a review of existing reviewer training programmes. 
journal impact factor (JIF) - which has reigned over other metrics levels, such as document- or author-level metrics (Thomas \& Murphy, 2018). The San Francisco Declaration on Research Assessment (DORA 2012) is an example of the new directions that research evaluation practices should take in open science.

Journal-level metrics have been based on the numbers of article citations in a specific journal at a specific period. This is the case of the journal impact factor (Clarivate Web of Science) and CiteScore (Scopus). The journal impact factor has been widely criticised (DORA, 2012), as (a) it has been used to compare the scientific production of individual researchers and institutionsinstead of employing document- and author-level metrics to this end-; (b) it is easily manipulated by editorial policy; and (c) the data used to calculate it are not transparent nor publicly accessible (see Larivière \& Sugimoto, 2019 for a discussion on these and other limitations of the journal impact factor). In addition to a comprehensive list of recommendations for various agents involved in the scientific community, DORA provides a general recommendation: stop using the journal impact factor and other journal-level metrics to measure the quality of individual articles and the scientific production of scholars, let alone to reach decisions in hiring, promotion, and funding.

Shifting away from journal-level metrics calls for developing other metrics that facilitate a transparent evaluation, in line with the publishing practices introduced with open science. Document-level metrics - specifically, altmetrics - could fill this gap. Altmetrics is a set of metrics aiming to assess a text's social impact based on the social web (Funamori, 2017). They reflect the amount of attention a research output has attracted (mentions in mass-media news and in tweets, pageviews, downloads, etc.), how information is disseminated - social sharing, news coverage, etc - and the influence and impact of a research output, such as references to the output in public policies, mentions by experts and practitioners, etc. (Altmetric, n.d.).

Altmetrics have potential but are relatively recent, and much bibliometric research is still necessary. Applying altmetrics for research evaluation faces many challenges and criticisms (Tahamtan \& Bornmann, 2020). Firstly, a growing number of investigations correlate altmetrics with traditional impact measures, such as citations (see Costas, Zahedi \& Wouters, 2015), but many scholars and institutions feel that it is still not clear whether altmetrics really measure impact or attention (Gruber, 2014). Second, the use and acceptance of social media (the main platform for altmetrics) varies widely due to factors such as age, academic rank and status, gender, discipline, country, and language (see Sugimoto et al., 2017 for a comprehensive review of these factors). These factors reduce (or boost) altmetric indicators. Third, altmetric aggregators, i.e., platforms that compile metrics based on social media interactions and events, do not compile the same indicators. Hence, the quality of altmetric data is not always ideal and stable. In addition, aggregators mainly collect data on documents with a DOI, which limits the type of documents that are tracked (mainly journal articles; see Gorraiz et al., 2016). Moreover, in comparison to the STEM disciplines, the use of DOIs is less frequent in social sciences and the humanities, and consequently altmetrics do not perform as well in social impact measurement as they do in STEM disciplines (Yang et al., 2021). A fourth challenge with altmetrics is standardisation since they are field-independent metrics. For instance, the number of scholars working in TIS is lower to that of scholars working in medicine, so the possible interactions in the social web are fewer in TIS. Furthermore, altmetrics, like any scientific quality metrics, can be misused, for example by extreme self-promotion.

To date (April 2021; DORA, 2021c), more than 19,000 individuals and organisations in 145 countries have signed the DORA declaration. Now, signing the declaration and implementing it are different actions. Very few universities and institutions thus far have adopted the recommendations established in the 
declaration, and most of them are found in the European Union (DORA, 2021a). However, many learned societies and research institutions have drafted position papers and guidelines of good practices (DORA, 2021b). Two of the most wellknown documents derived from DORA are the "Leiden Manifesto for research metrics" (Hicks et al., 2015) and "The Hong Kong Principles for assessing researchers" (Moher et al., 2020) but their implementation is, again, limited. ${ }^{9}$ The future of these initiatives is uncertain, but it is possible that, if the pressure to modify the current research evaluation system increases, the mismatch between the number of signatories to declarations such as DORA and the number of institutions implementing the recommendations described therein may decrease.

\section{Applying open-science practices to translation and interpreting studies}

This section focuses on how cross-disciplinary open-science practices have been applied to TIS, while contextualising them in the publishing practices of the discipline.

\subsection{Open access}

OA research outputs have steadily increased since OA was introduced in TIS. At least $46.6 \%$ of all TIS research outputs published from 2011 to 2015 were OA (Franco Aixelá, Olalla-Soler \& Rovira-Esteva, 2021). Adopting OA publishing practices is format-dependent: whereas almost $46 \%$ of the journal articles published from 1961 to 2015 in TIS are OA, only 3.9\% of books are. In fact, to our knowledge only a single full OA book series exists: "Translation and Multilingual Natural Language Processing", edited by Czulo, HansenSchirra, Rapp, and Bisiada. ${ }^{10}$ Not surprisingly, the fraction of book chapters published in open access is also correspondingly small (12.6\%). In the case of $\mathrm{PhD}$ theses, in recent years public institutions have been allowing free access, and almost $80 \%$ of the $\mathrm{PhD}$ theses published from 2011 to 2015 are now available in OA. Hence, here the spotlight is on journals and their articles, where variation is higher.

The boost of OA publishing in TIS is largely due to new OA journals and to the transformation of many toll-access journals to OA publishing models. In 2020, TIS features a wide spectrum of journal types: toll-access, hybrid, gold $\mathrm{OA}$ and diamond journals. Table 1 displays the specifics of open publishing in TIS. Based on BITRA's cut-off point, journals labelled core are those with at least $50 \%$ of the articles devoted to a TIS-related topic. Peripheral journals state that they welcome articles on translation or interpreting but do not reach the $50 \%$ threshold of articles related to TIS. The list of journals was retrieved from RETI. ${ }^{11}$

\footnotetext{
${ }^{9}$ See Gadd (2020) for a critique of Elsevier's endorsement of the Leiden Manifesto over DORA and the implications of such preference.

${ }^{10}$ Book series not published in open access by default have not been included here.

${ }^{11}$ As discussed in Franco Aixelá, Olalla-Soler \& Rovira-Esteva, (2021), the coverage of BITRA and RETI is not optimal concerning TIS publications from non-Western countries. Nevertheless, these two databases are the most appropriate ones for the present study. Scopus only indexes articles from 111 (51.4\%) of the 216 journals extracted from RETI and from 41 (36.9\%) of the 111 TIS core journals that are systematically covered in BITRA. In the case of Web of Science, articles are indexed from $55(25.5 \%)$ of the 216 journals indexed in RETI and from $13(11.7 \%)$ of the 111 TIS core journals covered in BITRA.
} 
Table 1. A panoramic view of TIS peer-reviewed journals (June 2020)

\begin{tabular}{|c|c|c|c|c|c|c|c|}
\hline & & \multicolumn{2}{|c|}{ core $(n=111)$} & \multicolumn{2}{|c|}{ peripheral $(n=105)$} & \multicolumn{2}{|c|}{ total $(n=216)$} \\
\hline & & $\mathrm{n}$ & $\%$ & $\mathrm{n}$ & $\%$ & $\mathrm{n}$ & $\%$ \\
\hline \multirow{4}{*}{ 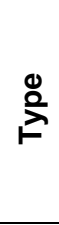 } & Toll access & 9 & 8.1 & 9 & 8.6 & 18 & 8.3 \\
\hline & Hybrid & 22 & 19.8 & 48 & 45.7 & 70 & 32.4 \\
\hline & Gold & 2 & 1.8 & 5 & 4.8 & 7 & 3.2 \\
\hline & Diamond & 78 & 70.3 & 43 & 41.0 & 121 & 56.0 \\
\hline \multicolumn{8}{|c|}{ Full self-archiving } \\
\hline \multirow{9}{*}{ 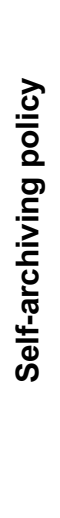 } & Toll access & 0 & 0 & 0 & 0 & 0 & 0 \\
\hline & Hybrid & 21 & 95.5 & 36 & 75 & 57 & 81.4 \\
\hline & Gold & 2 & 100 & 5 & 100 & 7 & 100 \\
\hline & Diamond & 75 & 96.2 & 43 & 100 & 118 & 97.5 \\
\hline & \multicolumn{7}{|c|}{ Delayed self-archiving } \\
\hline & Toll access & 1 & 11.1 & 2 & 22.2 & 3 & 16.7 \\
\hline & Hybrid & 1 & 4.5 & 12 & 25 & 13 & 18.6 \\
\hline & Gold & - & - & - & - & - & - \\
\hline & Diamond & - & - & - & - & - & - \\
\hline \multirow{10}{*}{ 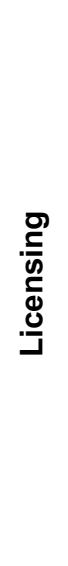 } & \multicolumn{7}{|c|}{ Copyright } \\
\hline & Toll access & 9 & 100 & 8 & 88.9 & 17 & 94.4 \\
\hline & Hybrid & 22 & 100 & 48 & 100 & 70 & 100 \\
\hline & Gold & 0 & 0 & 2 & 40 & 2 & 28.6 \\
\hline & Diamond & 14 & 17.9 & 6 & 14 & 20 & 16.5 \\
\hline & \multicolumn{7}{|c|}{ Creative Commons } \\
\hline & Toll access & 0 & 0 & 0 & 0 & 0 & 0.0 \\
\hline & Hybrid & 0 & 0 & 0 & 0 & 0 & 0.0 \\
\hline & Gold & 2 & 100 & 3 & 60 & 5 & 71.4 \\
\hline & Diamond & 42 & 53.8 & 29 & 67.4 & 71 & 58.7 \\
\hline \multirow{4}{*}{$\begin{array}{l}00 \\
\frac{0}{\alpha}\end{array}$} & Toll access & - & - & - & - & - & - \\
\hline & Hybrid & 22 & 100 & 48 & 100 & 70 & 100.0 \\
\hline & Gold & 2 & 100 & 5 & 100 & 7 & 100.0 \\
\hline & Diamond & - & - & - & - & - & - \\
\hline \multirow{10}{*}{ 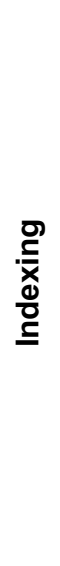 } & \multicolumn{7}{|c|}{ In Journal Citation Reports } \\
\hline & Toll access & 0 & 0 & 0 & 0 & 0 & 0 \\
\hline & Hybrid & 11 & 50 & 37 & 77.1 & 48 & 68.6 \\
\hline & Gold & 0 & 0 & 0 & 0,0 & 0 & 0,0 \\
\hline & Diamond & 2 & 2.6 & 5 & 11.6 & 7 & 5.8 \\
\hline & \multicolumn{7}{|c|}{ In Scopus } \\
\hline & Toll access & 1 & 11.1 & 4 & 44.4 & 5 & 27.8 \\
\hline & Hybrid & 18 & 81.8 & 47 & 97.9 & 65 & 92.9 \\
\hline & Gold & 0 & 0,0 & 1 & 20 & 1 & 14.3 \\
\hline & Diamond & 22 & 28.2 & 18 & 41.9 & 40 & 33.1 \\
\hline
\end{tabular}


Note: data on active journals (i.e., with at least one issue published since 2018), retrieved from RETI, BITRA, Scopus, Journal Citation Reports and SHERPA/RoMEO. Journal Citation Reports and Scopus data belong to the journal impact factor and CiteScore 2019 indexes. Full data in Appendix.

The economic model of hybrid journals (20\% of all core journals and $45.3 \%$ of the peripheral ones) is still mainly based on subscriptions. If Plan S is widely adopted in the upcoming years, the share of OA articles published by hybrid journals will probably decrease. This would oblige such titles to consider their future economic sustainability, and conceivably induce them to shift to a gold OA model (i.e., full OA journals asking authors to pay APCs) or return to a toll-access one. ${ }^{12}$

While all hybrid journals allow for self-archiving (green OA) with or without embargo, almost no toll-access journal informs whether it accepts selfarchiving. However, the overall percentage of TIS journal articles that could be made public through a gold or a green route is extremely large: at the time of writing these options are possible in $90 \%$ of the core journals and $93.4 \%$ of the peripheral ones, with the overall figure (core + peripheral journals) being $91.7 \%$.

Let us now consider APCs (Table 2). A comparison of the results in Table 2 to those for the whole pool of OA journals indexed in the Directory of Open Access Journals in 2017 (Morrison, 2018) shows that the mean APC for core + peripheral TIS gold OA journals $(\mathrm{m}=\$ 274)$ is much lower than the one computed by Morrison $(\mathrm{m}=\$ 974 ; \mathrm{Mdn}=\$ 750)$. However, the mean APC in core + peripheral TIS journals $(\mathrm{m}=\$ 2,253)$ is twice that of DOAJ-indexed journals $(\mathrm{m}=\$ 974)$. Given that all TIS core hybrid journals are published by for-profit publishers, this substantial difference raises a thorny question: What constitutes an ethically appropriate profit margin for these publishing companies, given that their OA articles bring them dual revenues - individually through the respective APCs, and collectively via institutional subscriptions?

Table 2. APCs in TIS academic journals (in USD; June 2020)

\begin{tabular}{|c|c|c|c|c|c|}
\hline $\begin{array}{l}\text { Core journals } \\
(n=111)\end{array}$ & $\begin{array}{c}\text { Global } \\
(n=24)\end{array}$ & $\begin{array}{c}\text { Toll } \\
\text { access } \\
(n=0)\end{array}$ & $\begin{array}{c}\text { Hybrid } \\
(n=22)\end{array}$ & $\begin{array}{c}\text { Gold } \\
(n=2)\end{array}$ & $\begin{array}{c}\text { Diamond } \\
(n=0)\end{array}$ \\
\hline Mean & 2,062 & & 2,235 & 155 & \\
\hline Median & 1,905 & & 1,905 & 155 & \\
\hline SD & 832 & & 617 & 64 & \\
\hline Max. & 3,000 & - & 3,000 & 200 & \\
\hline Min. & 110 & & 1,008 & 110 & \\
\hline Interquartile range & 1,090 & & 1,090 & 90 & \\
\hline $\begin{array}{l}\text { Peripheral journals } \\
(\mathrm{n}=105)\end{array}$ & $\begin{array}{c}\text { Global } \\
(n=53)\end{array}$ & $\begin{array}{c}\text { Toll } \\
\text { access } \\
(n=0)\end{array}$ & $\begin{array}{l}\text { Hybrid } \\
(n=48)\end{array}$ & $\begin{array}{l}\text { Gold } \\
(n=5)\end{array}$ & $\begin{array}{l}\text { Diamond } \\
(\mathrm{n}=0)\end{array}$ \\
\hline Mean & 2,484 & & 2,709 & 322 & \\
\hline Median & 2,980 & & 2,995 & 200 & \\
\hline SD & 901 & - & 588 & 188 & . \\
\hline Max. & 4,000 & & 4,000 & 550 & \\
\hline Min. & 157 & & 1,300 & 175 & \\
\hline Interquartile range & 754 & & 759 & 302 & \\
\hline $\begin{array}{l}\text { Total } \\
(n=216)\end{array}$ & $\begin{array}{l}\text { Global } \\
(n=77)\end{array}$ & $\begin{array}{l}\text { TA } \\
(n=0)\end{array}$ & $\begin{array}{l}\text { Hybrid } \\
(\mathrm{n}=70)\end{array}$ & $\begin{array}{l}\text { Gold } \\
(n=7)\end{array}$ & $\begin{array}{l}\text { Diamond } \\
(\mathrm{n}=0)\end{array}$ \\
\hline Mean & 2,253 & & 2,560 & 274 & \\
\hline Median & 2,700 & & 2,801 & 200 & \\
\hline SD & 896 & & 633 & 176 & \\
\hline Max. & 4,000 & & 4,000 & 550 & \\
\hline Min. & 110 & & 1,008 & 110 & \\
\hline Interquartile range & 1,090 & & 1,090 & 345 & \\
\hline
\end{tabular}

\footnotetext{
${ }^{12}$ See Russell (2019) for a discussion of the issues that might lead to such scenario.
} 
Note: data retrieved from publishers' websites. APCs were current at the time of writing. Figures converted to USD to facilitate comparison with Morrison's (2018) results. No information on waiver or discount policies was compiled. Full data in Appendix.

Several scholars have acknowledged a tendency to view TIS from two coexisting perspectives. Moser-Mercer (1994) distinguishes between the "natural science paradigm" and the "liberal arts paradigm" within interpreting studies. Gile (2013) differentiates "canonical scientific culture" from "human science culture" in TIS. Latterly the sciences-humanities differentiation has been heavily criticised for being a conceptual artefact that was shaped by "British empiricism" (Wierzbicka, 2011, p. 31; see Bouterse \& Karstens, 2015 for a history of the opposition between humanities and sciences). Nevertheless, whilst the methods and approaches of the sciences and the humanities are becoming increasingly intertwined, TIS research could be perceived from a more humanistic-oriented or a more social science-oriented perspective.

Overall, as shown in Lara (2015), authors tend to cover the costs of APCs. This has negative consequences for authors conducting humanistic-oriented research projects (Tenopir et al., 2017), which are associated with lower funding (Eve, 2015). Estimating the proportion of TIS humanistic-oriented research that is funded and that of TIS social science-oriented research is complex due to the diversity of existing funding sources and the poor coverage of such information in both general and TIS-specific bibliographic databases. However, if such a general trend is also true for TIS, then underfunded (or simply unfunded) scholars - such as those in humanistic-oriented research - may be unable to meet APCs, ${ }^{13}$ thereby preventing them from publishing in many journals that use a gold OA route. This would raise a clearly unethical distinction between funded and non-funded scholars. Furthermore, it may miss important contributions to knowledge advancement. In section 2.1.1, we discussed the possible negative consequences of APCs for scholars in low- and middleincome countries. In TIS, $81.5 \%$ of the articles that appeared in TIS core journals included in Scopus were published by authors affiliated with institutions located in high-income countries (Table 3). They represent 53.5\% of all countries of affiliation in this corpus of articles. Low-, lower-middle- and upper-middle-income countries (the remaining $46.5 \%$ ) account for $18.5 \%$ of all articles in TIS core journals indexed in Scopus. Hence, we could argue that TIS articles tend to be published mainly in high income countries. What would be the consequences of APCs for the other countries (almost half) in which research on translation and interpreting is being carried out? It is impossible to predict the future, but as discussed in previous sections, the strong likelihood that APCs could exacerbate the current division between low, middle, and highincome countries in terms of academic publishing should not be ignored.

One could possibly argue that no scholar is forced to publish in gold OA or hybrid journals, as numerous TIS core journals (in fact, the majority) are situated in the diamond category (Table 1). However, many countries require scholars to publish articles in indexed journals for research evaluation purposes, with Web of Science and Scopus being the two main frameworks of reference (Table 4).

\footnotetext{
${ }^{13}$ Authors who are not native English speakers and wish to publish in English often have to assume the costs of translating or proof-reading their publications as well (See Franco Aixelá, Olalla-Soler \& Rovira-Esteva, 2021 for a discussion of the predominance of English as a publication language in TIS). If they also need to pay for APCs, the situation becomes even worse.
} 
Table 3. Distribution of articles published in TIS core journals indexed in Scopus $2020(n=41)$ by income level of the country of affiliation

\begin{tabular}{lc}
\hline & $\begin{array}{c}\text { Articles in TIS core journals indexed in } \\
\text { Scopus }(\mathrm{n}=9448)\end{array}$ \\
\hline Low-income countries $(\mathrm{n}=1 ; 0.99 \%)$ & $3(0.03 \%)$ \\
Lower middle-income countries & $135(1.43 \%)$ \\
( $\mathrm{n} 18=17.82 \%)$ & \\
Upper middle-income countries & $1612(17.06 \%)$ \\
( $\mathrm{n} 28=27.72 \%)$ & $7698(81.48 \%)$ \\
High-income countries $(\mathrm{n}=54 ; 53.47 \%)$ & \\
\hline
\end{tabular}

The World Bank 2020 classification of countries by income level was used. Palestine is listed as a country in Scopus but not in the World Bank list. When an article is published by $n$ authors, it is counted $n$ times. Full data in Appendix (Sheet 2).

Table 4. Core TIS journals indexed in Scopus and in Web of Science and their CiteScore and JIF 2019 quartiles

\begin{tabular}{lrrrrrrrr}
\hline \multirow{2}{*}{$\begin{array}{l}\text { TIS core } \\
\text { journals }\end{array}$} & \multicolumn{2}{c}{$\begin{array}{c}\text { TA } \\
(\mathrm{n}=9)\end{array}$} & \multicolumn{2}{c}{$\begin{array}{c}\text { Hybrid } \\
(\mathrm{n}=22)\end{array}$} & \multicolumn{2}{c}{$\begin{array}{c}\text { Gold OA } \\
(\mathrm{n}=2)\end{array}$} & \multicolumn{2}{c}{$\begin{array}{c}\text { Diamond } \\
(\mathrm{n}=78)\end{array}$} \\
\cline { 2 - 11 } & $\mathrm{n}$ & \multicolumn{1}{c}{$\%$} & $\mathrm{n}$ & \multicolumn{1}{c}{$\%$} & $\mathrm{n}$ & $\%$ & $\mathrm{n}$ & \multicolumn{1}{c}{$\%$} \\
\hline CiteScore & $\mathbf{1}$ & $\mathbf{1 1 . 1}$ & $\mathbf{1 8}$ & $\mathbf{8 1 . 8}$ & $\mathbf{0}$ & $\mathbf{0}$ & $\mathbf{2 2}$ & $\mathbf{2 8 . 2}$ \\
\hline Q1 & 0 & 0 & 10 & 55.6 & & & 4 & 18.2 \\
Q2 & 1 & 100 & 5 & 27.8 & & - & 5 & 22.7 \\
Q3 & 0 & 0 & 2 & 11.1 & & & 9 & 40.9 \\
Q4 & 0 & 0 & 1 & 5.5 & & & 4 & 18.2 \\
\hline JIF & 0 & $\mathbf{0}$ & $\mathbf{1 1}$ & $\mathbf{5 0}$ & $\mathbf{0}$ & $\mathbf{0}$ & $\mathbf{2}$ & $\mathbf{2 . 6}$ \\
\hline Q1 & & & 0 & 0 & & & 0 & 0 \\
Q2 & & & 2 & 18.2 & & & 0 & 0 \\
Q3 & & & 7 & 63.6 & & & 2 & 100 \\
Q4 & & & 2 & 18.2 & & & 0 & 0 \\
\hline
\end{tabular}

Note: full data in Appendix (Sheet 1).

Research evaluators who expect articles to have been published in journals indexed in Web of Science are forcing TIS scholars to publish in hybrid journals, which in turn charge APCs for OA publishing using the gold route. The situation is less drastic when Scopus-indexed journals are also accepted for evaluation purposes.

In TIS, there has been a strong shift toward OA publishing in journals in the last decades, but there is still much to be done in the case of books and book chapters. Successfully attracting scholars to publishing OA books and articles is strongly dependent on research evaluation practices. In the event that DORA is implemented in research evaluation globally, we might eventually discern a clear tendency toward OA publishing. TIS scholars and researchers will also need to take an active role: they will need to engage in discussions on the relevance and need of OA in TIS and decide how to act according to their views, values, and possibilities.

Until such change occurs, OA journal editors and non-profit publishers will likely need to persevere with their arduous efforts to have (or keep) their journals indexed so as to attract more scholars. The future of hybrid journals is uncertain, in view of their high APCs (which generally can be met only by funded scholars) and the still unknown adoption rate of Plan S and its incidence in academic publishing. In a discipline where humanistic-oriented and social science-oriented research converge, an increase in the adoption of APC charges may be extremely harmful for scholars conducting humanistic-oriented research and may exacerbate an unnecessary and dangerous schism between funded and non-funded researchers. 


\subsection{Open data}

Sharing research data is rather infrequent in TIS. There is no discipline-specific data repository in TIS, while other disciplines have created their own. ${ }^{14}$ This makes quantifying the adoption of open data in TIS rather difficult, since scholars may choose to share data as supplementary materials uploaded to the publishing venue where they published their research, or they may use general repositories, such as Dryad, Figshare, or Zenodo. With translation and interpreting as separate search keywords, Dryad yields zero datasets; FigShare, around 40; and Zenodo, around $330 .{ }^{15}$ In short, the use of general repositories seems to be infrequent. Unfortunately, the number of journal articles including datasets as supplementary materials also seems difficult to quantify, so that estimating frequency (or lack thereof) is based purely on impression - not very reliable. Scholars may also use their institutional repositories to make their data accessible or create their own public databases (such as the CRITT Translation Process Database) $;{ }^{16}$ there are also the many portals that provide open and free access to translation and interpreting corpora (such as the Chinese/English Political Interpreting Corpus). ${ }^{17}$ Such information is widely scattered, and TIS would benefit from a comprehensive study to assess the adoption of this practice.

Several scholars have argued for data sharing. Göpferich (2010) contended that the lack of data sharing in translation process research was extendable to the whole discipline. She called for more data to be shared, and proposed ways to standardise metadata to facilitate re-using datasets. Open data could also foster replication in TIS, which is rather infrequent (Olalla-Soler, 2020). Besides replication, open data could also facilitate carrying out meta-analyses (Mellinger \& Hanson, 2020), which are still scarce in our discipline and could provide sound findings to many topics. Another benefit of open data for TIS is discussed in Bowker and Delsey (2016). In the context of big data, the authors argue that sharing data such as translation memories or large linguistic datasets may help to improve statistical machine translation platforms and term extractors. However, all these advantages are no longer beneficial if ethical considerations are disregarded, as discussed in section 2.1.2. In the specific case of research in the language industry, Mellinger (2020) discusses a conflictive situation for the researcher in that companies may request more information beyond what has been published and for which the participants have not given express permission. The uses of the collected data should always be clearly established in advance, so that the informed consent signed by the participants includes all expected uses. In the event that new, unforeseen purposes arise, researchers should seek explicit permission from the participants and, should they refuse to grant it, ensure that their data will not be used. As pointed out by Mellinger and Baer (2021) scholars conducting corpus-based studies should also reflect on ethical considerations regarding corpus data compilation and the re-use of such data.

Open data is mainly applicable to empirical TIS research based on quantitative, qualitative, and mixed-method studies. While the percentage of published research outputs based on such approaches is difficult to quantify,

\footnotetext{
${ }^{14}$ A list of data repositories by discipline can be found here: http://oad.simmons.edu/oadwiki/Data repositories.

${ }^{15}$ Results had to be refined through limiting them by discipline or by keyword. Only datasets were counted here, and pre-print and post-print versions of publications were excluded. The queries were performed on April 11, 2021. Figures are approximate (especially in Zenodo), as it is not always obvious whether the dataset is related to a study on some aspect of translation or interpreting or whether it is part of a study in some other discipline in which translation or interpreting has been used as a medium, not as an object of study.

16 The CRITT TPR-DB can be accessed at:

https://sites.google.com/site/centretranslationinnovation/tpr-db

${ }^{17}$ THE CEPIC corpus can be accessed at: https://digital.lib.hkbu.edu.hk/cepic/
} 
there seems to be generally assumed that such research has increased in recent years, especially in several research fields such as interpreting (Liu, 2011), translation and cognition (Muñoz 2014), audiovisual translation (Orero et al., 2018), and machine translation (Gupta \& Dhawan, 2019), among others.

Publishers could introduce ways to incentivise open data, such as the open science badges designed by the Open Science Foundation (OSF) and the Center for Open Science (COS). While badges per se are no guarantee of quality (critique in Ioannidis, 2016), they seem to be a useful way of increasing public data sharing. Before the awarding of open data badges to psychology journals, only $3 \%$ of their articles reported open data; subsequently that proportion increased to $23 \%$ (Kidwell et al., 2016). In TIS, where open data seems to be almost non-existent, awarding such badges would possibly help us initiate a critical reflection on the need and usefulness of sharing data publicly. It might also help us change our attitudes towards a greater acceptance of possible criticisms when other researchers re-run our analyses and identify errors.

\subsection{Open methods and tools}

Searches for detailed descriptions of the methodological process followed in the studies, i.e., open methods, in Dryad, Figshare, and Zenodo yielded zero results. ${ }^{18}$ Github does yield many results, mainly related to tools. However, given the limited advanced search options of the repository, it is complex to filter out those that are not related to research. This could indicate that methodological descriptions tend to be only included in specific sections of publications derived from empirical studies. Such practice leads to the following question: Given that most publication formats have limitations of space (mainly by page or word counts), are methodological descriptions of empirical studies in TIS publications detailed enough to allow other scholars to replicate them as closely as possible? The answer is unclear, and TIS would benefit from investigations seeking to answer this question. The picture is less blurred when it comes to reporting (statistical) findings. As Mellinger \& Hanson (2019) found in a meta-analytical study on working memory in simultaneous interpreting, statistical results are frequently not fully reported, and null results are often not reported at all. This renders the process of conducting such studies more complex, since missing information needs to be calculated or estimated. As a result of the efforts by several authors to share good practices for the correct use of statistics and the reporting of statistical results (see Ferraresi, 2020; Mellinger \& Hanson, 2017), such problems are likely to be reduced in the future.

TIS publications tend to include the tools used to gather and analyse data in the respective studies. Questionnaires, for example, frequently feature as appendices, as do source texts for translation or interpreting tasks. Now, if these appendices are part of a research output (a book, an article, etc.) not published in OA, they will not be publicly accessible.

Open data and tools are closely related to pre-registration. There exists an OSF pre-registration registry, which retrieves pre-registrations from OSF, Clinical Trials, and Research Registry. An OSF pre-registration search using either translation or interpreting as keywords returned 55 pre-registered studies. This is $0.02 \%$ of the 310,306 pre-registered studies in June 2020. In all, 51 of the 55 pre-registered TIS studies $(92.7 \%)$ dealt with the validation of the translation of questionnaires or scales (see Appendix, Sheet 3); two of them (3.6\%), with lexical retrieval in bilinguals; one $(1.8 \%)$, with the effects of iconicity in American Sign Language; and one (1.8\%), with remote medical interpreting.

The methods of TIS studies involving human participants are likely to be reviewed by an ethics committee or institutional review board. Even if the

${ }^{18}$ Search performed in April 2021. 
purpose of such procedure is different from that of pre-registering a study, it involves describing the methods and tools that will be used. Hence, the reports sent to such committees and boards (if approved) may serve as evidence that the researchers have pre-established what methods will be followed, how data will be collected, how it will be analysed, stored and reported (Mellinger \& Baer, 2021).

Open methods and tools and pre-registration are mainly applicable to empirical TIS research based on quantitative, qualitative, and mixed-method studies. Fostering pre-registration in TIS would require a change in attitudes among scholars given that the field believes that pre-registration is of little application (Olalla-Soler, 2020). Awarding pre-registration badges in publishing venues, like those by OSF and COS, might foster changes in attitudes. TIS publishers could also adopt (or adapt) available resources to foster open methods and tools, such as the Transparency Checklist (Aczel et al., 2020). ${ }^{19}$

\subsection{Open peer-review}

Ross-Hellauer (2017) identified seven traits of open peer-review. An examination of the peer-review practices of the 216 core + peripheral TIS journals (Appendix, Sheet 1) shows that not one of them allowed either open identities, open reports, open participation, open interaction, or open platforms. Only open pre-review and open final-version commenting seem to exist. However, they do not necessarily happen in the interface of the publishing venue, but in repositories (such as Academia.edu and ResearchGate, which allow comment posting). An exception would be the journal Translation Studies, which welcomes responses to published papers.

During the first stage of a shift towards open peer-review, TIS publishers and editors should probably allow authors and reviewers to decide whether to take part in open peer-review practices. Open identities, open reports and open participation are the most frequent combination of open peer-review practices (Ross-Hellauer, 2017). However, introducing them at the same time could have a negative effect both on authors and reviewers, as these could be perceived as too many changes at once. Moreover, scholars' perception of the benefits of open peer review depends on the specific practice: in the study conducted by Ross-Hellauer, Deppe \& Schmidt (2017), open interaction and open reports were perceived as positive, but the participants' attitude toward open identities was generally negative. Editors and publishers willing to shift to open peerreview should implement these practices step by step, possibly commencing with those practices toward which scholars have indicated a greater degree of acceptance. In the absence of a comprehensive survey of the attitudes of TIS scholars regarding open peer-review and their inclination to accept such practices, editors could conduct smaller-scale studies with their pool of reviewers and published authors to determine how feasible these changes are.

\subsection{Open research evaluation}

We have already discussed specific practices that would influence open research evaluation. As discussed in $\S 2.1 .5$, many of the potential changes in research evaluation practices in the near future will depend on adopting DORA (2012). TIS scholars can also help speed those changes by asking their institutions to sign DORA and by starting to explore the possibility of implementing DORA's recommendations for authors. TIS editors and publishers can also apply specific recommendations to their venues, shifting toward a promotion strategy focused less on using journal-level metrics and more on integrating of document-level ones.

${ }^{19}$ A short version of the scale is accessible at: http://www.shinyapps.org/apps/ShortTransparencyChecklist/ 
In the meantime, TIS scholars will have to be evaluated with current practices, which encourage publication by journals and book publishing houses included in impact-oriented lists, mainly on the basis of the number of citations accrued in a specific time window. Similarly, TIS OA journal editors will probably need to maintain their efforts to be (or stay) indexed in such lists, so as to keep increasing OA publishing while attracting more scholars to their journals. In the case of toll access or hybrid journals wishing to transition to an OA model, extensive research has shown the benefits of doing so. For instance, citations to articles tend to increase (Archambault et al., 2016) and, as a consequence, so does impact measured with journal-level metrics (Momeni et al., 2021). ${ }^{20}$ Another positive consequence is that the number of articles by authors from low- and middle-income countries increases (Bautista-Puig et al., 2020). Integrating altmetric indicators into published articles would help scholars to easily obtain document-level metrics.

Contextualisation of research productivity and impact is a key factor to achieve a holistic, multi-faceted evaluation. This is especially important in TIS, often grouped with disciplines such as linguistics and humanities for evaluation purposes. Publication, citation and even authorship patterns in TIS differ greatly from those disciplines. Thus, being able to explain what is normal, frequent or in line with the practices of the discipline is of paramount importance for research evaluation. Bibliometric research in TIS has already started to provide such descriptions. Some of the results obtained so far have also challenged some of the evaluation criteria of agencies around the world. In some countries, research evaluation agencies consider that publishing books is not as worthy as publishing journal articles. However, Franco Aixelá, Olalla-Soler \& RoviraEsteva, (2021) showed that, in TIS, the median number of citations accrued by books ${ }^{21}$ is higher than that of journal articles, whereas articles and book chapters have a similar median number of citations. Hence, TIS books (and thus book chapters) receive significant attention and should not be considered less important than articles for evaluation purposes in our discipline. Other agencies consider that the merit of a co-authored publication is lower than that of a singleauthored document. Rovira-Esteva, Franco Aixelá \& Olalla-Soler (2020) showed that around $25 \%$ of TIS publications between 2011 and 2015 were coauthored, especially articles and edited volumes. Currently, the average number of authors across all TIS publications is 1.3 and, in co-authored documents, 2.6. In short, co-authored documents by 2-3 scholars are frequent, and coauthorship is on the rise. Other agencies use journal-level metrics with a 2 or 3year citation window. As shown by Rovira-Esteva, Franco Aixelá \& OlallaSoler (2019), a 2-year citation window can only detect a range between $13.9 \%$ and $20.1 \%$ of the citations accrued by a TIS publication. A 5-year citation window detects between $39 \%$ and $42.5 \%$ of the accrued citations. Hence, an adequate citation window for TIS would be 6-7 years. Indicators based on citation windows under 5 years should be disregarded.

Bibliometric information is a driver for a better, more contextualised research evaluation. It can also help us to more fully situate the discipline by providing a broader view of the state of the art, and may even hint at possible directions TIS might take in terms of research topics or methods (See for instance Franco Aixelá, 2018 for an overview of gender studies in TIS; and Ren \& Huang, 2021 for a map of interpreting research in China).

\footnotetext{
${ }^{20}$ According to the authors, the increase varies by discipline and takes more time in the case of social sciences than in other fields.

${ }^{21}$ Books refers both to monographs and edited books.
} 


\section{Concluding remarks}

The aims of this article were twofold. The first was to examine open science and its practices in a broad sense; the second was to relate that understanding squarely to TIS.

Open science is not a novel trend, and it cannot be reduced to open access, its most visible practice. Open science is complex, and a one-size-fits-all approach is not applicable across the disciplines. STEM disciplines have generally been the vantage point for describing open science, leaving publishing practices in the humanities and the social sciences aside. TIS is a complex discipline. The characteristics of humanistic-oriented and social scienceoriented research can be in greater or lesser harmony with some of the available open-science practices. Hence, some practices are quite frequent (such as OA), while others are non-existent, such as open peer-review. How far we can go in each practice is still unknown. Open-science practices that work in other disciplines may not be appropriate to TIS. Hence, each practice should be contextualised, and its benefits and drawbacks weighted in view of the existing publishing practices in our discipline.

The adoption of open-science practices depends on several factors. First, there is a philosophical component derived from one's own understanding of science and its role in society, and the extent to which one agrees with the core values of open science. Second, there is a technological component fostering the free circulation of, and access to, information, including scientific information. Third, there is a certain personal component, closely related to each scholar's academic position, career needs, and power relations. Combinations of these components may determine whether scholars are willing to adopt open-science practices and whether they are in the right position to do so. While bearing in mind the temporary and comprehensible drawbacks to adopting any new approach, Table 5 presents various recommendations for different actors who might be contemplating open-science practices.

Table 5. Recommendations for academic actors wishing to adopt open-science practices in TIS

\begin{tabular}{|c|c|c|}
\hline Open: & Actors & Whenever possible, consider: \\
\hline \multirow{11}{*}{$\begin{array}{l}\mathscr{\&} \\
\stackrel{d}{0} \\
\tilde{\pi}\end{array}$} & Authors & $\begin{array}{l}\text { Publishing in open access. When this is not possible, try using the } \\
\text { green open-access route when you need to publish in non-open- } \\
\text { access journals. }\end{array}$ \\
\hline & Reviewers & Prioritising reviews for non-profit, open-access publishing venues. \\
\hline & OA editors & $\begin{array}{l}\text { Using social networks to promote your venue to attract more } \\
\text { authors. }\end{array}$ \\
\hline & & $\begin{array}{l}\text { Basing your venue on a diamond model and asking associations or } \\
\text { institutions for funding to cover publication costs. }\end{array}$ \\
\hline & & Providing altmetric indicators to the documents you publish. \\
\hline & & Clearly stating under what license the documents are published in \\
\hline & & your venue and what authors are allowed to do with their \\
\hline & & $\begin{array}{l}\text { publication. } \\
\text { Keeping your RETI, DOAJ and Sherpa/RoMEO entries updated. }\end{array}$ \\
\hline & $\begin{array}{l}\text { Editors of } \\
\text { TA or hybrid }\end{array}$ & $\begin{array}{l}\text { Clearly stating whether green open access is allowed and under } \\
\text { what conditions. }\end{array}$ \\
\hline & venues & $\begin{array}{l}\text { Looking for ways to cut publication costs to reduce or suppress } \\
\text { APC charges. }\end{array}$ \\
\hline & $\begin{array}{l}\text { Evaluation } \\
\text { agencies }\end{array}$ & $\begin{array}{l}\text { Employing document and author-level metrics and eliminating or } \\
\text { reducing the weight of journal or publishing venue-level ones. }\end{array}$ \\
\hline \multirow{2}{*}{$\frac{\pi}{\frac{\pi}{0}}$} & Authors & $\begin{array}{l}\text { Uploading your data to a public repository and providing a link to it } \\
\text { in your publication. }\end{array}$ \\
\hline & & $\begin{array}{l}\text { Supplementing your data with metadata and information about } \\
\text { their quality. }\end{array}$ \\
\hline
\end{tabular}


Reviewers Asking the authors to upload their data if no information on data availability is provided.

Re-running the analyses so as to verify the reliability of the reported results, if you have the skills to do so and data is accessible.

Posting a data-sharing policy on your venue's website.

Editors Awarding badges to authors uploading their datasets to public repositories or to the publishing venue (in open access).

Evaluation Taking into account publicly shared datasets or databases as agencies research outputs for evaluation purposes.

Authors Uploading your methods descriptions and tools to a public repository and provide a link to them in your publication.

Pre-registering your research designs.

Reviewers Asking the authors to upload their methods description and tools if no information on their availability is provided.

$\begin{array}{ll}\frac{0}{0} & \\ \frac{0}{\infty} & \\ \infty & \\ 0 & \\ 0 & \\ \frac{0}{ \pm} & \text { Editors } \\ \stackrel{0}{E} & \end{array}$

Comparing the pre-registered methods description to the one given in the publication (if the study reported in the publication is preregistered) to determine if there are any changes and if these have been justified and transparently described.

Awarding badges to documents Uploading their methods descriptions and tools to public repositories or to the publishing venue (in open access). Adopting or adapting transparency lists to guide authors willing to upload their methods descriptions and tools to public repositories.

Evaluation Taking into account publicly shared methods descriptions and tools agencies as research outputs for evaluation purposes.

\begin{tabular}{|c|c|}
\hline \multirow{2}{*}{\multicolumn{2}{|c|}{ agencies }} \\
\hline & Authors \\
\hline & Reviewers \\
\hline 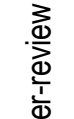 & Editors \\
\hline
\end{tabular}
$\begin{array}{ll}\text { Authors } & \text { Engaging in open peer-review practices. } \\ \text { Reviewers } & \text { Engaging in open peer-review practices. }\end{array}$

Surveying your pool of reviewers and previous authors to identify plausible open peer-review practices.

Paying reviewers for their work if the business model of the publishing venue is subscription- or APC-based.

Evaluation Taking into account public reviews as outputs for evaluation agencies purposes.

Authors Contextualising your academic productivity according to the trends in TIS when submitting research evaluation applications. Reporting author and document-level indicators such as altmetrics instead of only providing journal or publishing venue-based indicators.

Following the recommendations for scholars being evaluated given in the San Francisco Declaration (DORA).

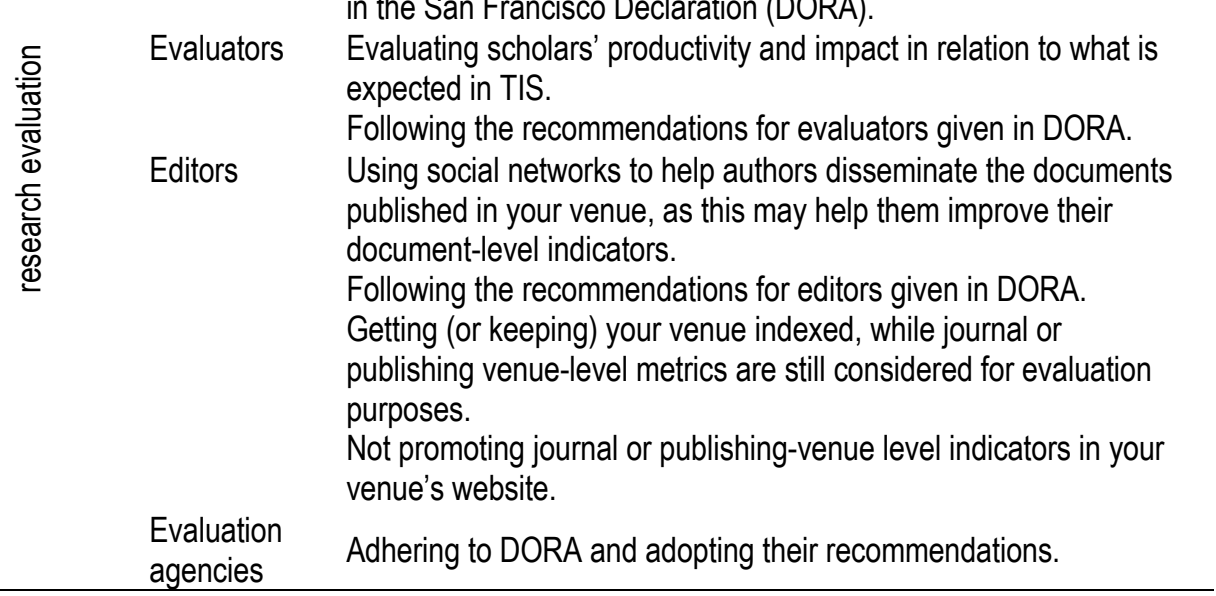

Note: some of these recommendations are based on Banks et al. (2019).

These recommendations should by no means be understood as an open call for boycotting current publishing practices, such as publishing in TA or hybrid journals. Several for-profit publishers provided a space for publishing and sharing ideas at the very beginning of our discipline, and those publications are 
to be considered our foundations. They still offer themselves today as highquality publishing venues, and disregarding them would be academically misguided and entirely inappropriate. Moreover, quality in academic publishing cannot be achieved by implementing open-science practices only. Best editorial practices $^{22}$ need to be observed by all publishing venues (be they book series, journals of any type, etc.) regardless of whatever open-science practices they follow or wish to adopt. ${ }^{23}$ In light of the above discussion, it is understandable if, in addition to our two previously stated aims, we now conclude with a third: namely that this article serve as a call for opening a debate on our publishing practices and the fostering of open science in our discipline. Let the discussion begin.

\section{Acknowledgements}

I would like to thank the editors and reviewers for their insightful comments on previous versions of this article. I would also like to express my gratitude to my colleagues Ricardo Muñoz Martín, Nicoletta Spinolo, César Andrés González, Javier Franco Aixelá and Sara Rovira-Esteva for their valuable suggestions on the first draft of the article. All of them helped me to improve the paper. Any shortcomings that are still there are my own responsibility.

\section{References}

Aczel, B., Szaszi, B., Sarafoglou, A., Kekecs, Z., Kucharský, Š., Benjamin, D., ... Wagenmakers, E. J. (2020). A consensus-based transparency checklist. Nature Human Behaviour, 4(1), 4-6. https://doi.org/10.1038/s41562-019-0772-6

Altmetric. (n.d.). What is altmetrics. Retrieved from https://www.altmetric.com/aboutaltmetrics/what-are-altmetrics

Appel, A. L., Albagli, S. \& MacIel, M. L. (2018). Open scientific journals: Emerging practices and approaches. Information Services and Use, 37(4), 475-488. https://doi.org/10.3233/ISU-170862

Archambault, É., Côté, G., Struck, B., \& Voorons, M. (2016). Research impact of paywalled versus open access papers. https://digitalcommons.unl.edu/ scholcom/29

Atkinson, D. (1998). Scientific discourse in sociohistorical context: The Philosophical Transactions of the Royal Society of London, 1675-1975. London: Routledge.

Baker, M. \& Penny, D. (2016). Is there a reproducibility crisis? Nature, 533(7604), 452-454. https://doi.org/10.1038/533452A

Bakker, M. \& Wicherts, J. M. (2011). The (mis)reporting of statistical results in psychology journals. Behavior Research Methods, 43(3), 666-678. https://doi.org/10.3758/s13428-011-0089-5

Banks, G. C., Field, J. G., Oswald, F. L., O’Boyle, E. H., Landis, R. S., Rupp, D. E. \& Rogelberg, S. G. (2019). Answers to 18 questions about open science practices. Journal of Business and Psychology, 34(3), 257-270. https://doi.org/10.1007. /s10869-018-9547-8

Bartling, S., \& Friesike, S. (2014). Towards another scientific revolution. In S. Bartling \& S. Friesike (Eds.), Opening science (pp. 3-15). Cham: Springer. https://doi.org/10.1007/978-3-319-00026-8

Bautista-Puig, N., Lopez-Illescas, C., de Moya-Anegon, F., Guerrero-Bote, V., \& Moed, H. F. (2020). Do journals flipping to gold open access show an OA citation or publication advantage? Scientometrics, 124(3), 2551-2575. https://doi.org/ 10.1007/s11192-020-03546-X

\footnotetext{
${ }^{22}$ A comprehensive collection of guidelines for best academic publishing and editorial practices is hosted on the website of the Committee on Publication Ethics: https://publicationethics.org/ guidance/Guidelines.

${ }^{23}$ See Pöchhacker \& Liu, 2021 for a discussion on plagiarism and predatory practices faced by the editors of Interpreting, and Valdeón, 2019 for a discussion on questionable practices by authors, editors, and reviewers.
} 
Bazerman, C. (1988). Shaping written knowledge. The genre and activity of the experimental article in science ( $1^{\text {st }}$ ed.). Madison, WI: University of Wisconsin Press.

Biblioteca d'Humanitats-UAB. (2013-2021). RETI: Revistes dels Estudis de Traducció i Interpretació. Retrieved from https:/www.uab.cat/libraries/reti

Bosman, J., Frantsvåg, J. E., Kramer, B., Langlais, P.-C., \& Proudman, V. (2021). The $O A$ diamond journals study. Exploring collaborative community-driven publishing models for Open Access. Part 1. https://doi.org/10.5281/zenodo. 4558704

Bouterse, J., \& Karstens, B. (2015). A diversity of divisions: Tracing the history of the demarcation between the sciences and the humanities. Isis, 106(2), 341-352. https://doi.org/10.1086/681995

Bowker, L., \& Delsey, T. (2016). Information science, terminology and translation studies. In Y. Gambier \& L. van Doorslaer (Eds.), Border crossings. Translation studies and other disciplines (pp. 73-96). Amsterdam: John Benjamins. https://doi.org/10.1075/btl.126.04bow

Bowler, P. J. (2009). Science for all. The popularization of science in early twentiechcentury Britain. Chicago: University of Chicago Press.

Bowman, N. D. \& Keene, J. R. (2018). A layered framework for considering open science practices. Communication Research Reports, 35(4), 363-372. https://doi.org/10.1080/08824096.2018.1513273

Budapest Open Access Initiative. (2002). Budapest Open Access Initative Declaration. Retrieved from https://www.budapestopenaccessinitiative.org/read

Burchardt, J. (2014). Researchers outside APC-financed open access. SAGE Open, 4(4), 215824401455171. https://doi.org/10.1177/2158244014551714

Burgelman, J.-C., Pascu, C., Szkuta, K., Von Schomberg, R., Karalopoulos, A., Repanas, K. \& Schouppe, M. (2019). Open science, open data, and open scholarship: European policies to make science fit for the twenty-first century. Frontiers in Big Data, 2(December), 1-6. https://doi.org/10.3389/fdata.2019.000 43

cOALition S. (2018). Plan S. Principles and Implementation. Retrieved from https://www.coalition-s.org/addendum-to-the-coalition-s-guidance-on-theimplementation-of-plan-s/principles-and-implementation

cOALition S. (2021). Transformative journals. Frequently asked questions. Plan S. https://www.coalition-s.org/transformative-journals-faq

Collins, F. S., Michael, M. \& Patrinos, A. (2003). The Human Genome Project: Lessons from large-scale biology. Science, 300(5617), 286-290. https://doi.org/10.1126/. science. 1084564

Committee on Publication Ethics. (2013). Ethical guidelines for peer reviewers. Retrieved from https://doi.org/10.24318/cope.2019.1.9

Costas, R., Zahedi, Z. \& Wouters, P. (2015). Do "altmetrics" correlate with citations? Extensive comparison of altmetric indicators with citations from a multidisciplinary perspective. Journal of the Association for Information Science and Technology, 66(10) 2003-2019. https://doi.org/10.1002/asi.23309

Despeaux, S. E. (2011). Fit to print? Referee reports on mathematics for the nineteenthcentury journals of the Royal Society of London. Notes and Records of the Royal Society, 65(3), 233-252. https://doi.org/10.1098/rsnr.2010.0066

DORA. (2012). San Francisco Declaration on Research Assessment. Retrieved from https://sfdora.org/read

DORA. (2021a). San Francisco Declaration on Research Assessment - Case studies. Retrieved from https://sfdora.org/dora-case-studies

DORA. (2021b). San Francisco Declaration on Research Assessment - Resources. Retrieved from https://sfdora.org/resource-library

DORA. (2021c). San Francisco Declaration on Research Assessment - Signers. Retrieved from https://sfdora.org/signers

Elliott, K. C., \& Resnik, D. B. (2019). Making open science work for science and society. Environmental Health Perspectives, 127(7), 1-7. https://doi.org/ 10.1289/EHP4808

Eve, M. P. (2015). Co-operating for gold open access without APCs. Insights, 28(1), 73-77. https://doi.org/10.1629/uksg.166

Fecher, B., \& Friesike, S. (2014). Open science: One term, five schools of thought. In S. Bartling \& S. Friesike (Eds.), Opening science (pp. 17-47). Cham, Switzerland: Springer. https://doi.org/10.1007/978-3-319-00026-8 
Ferraresi, A. (2020). Metodi statistici per gli studi sulla traduzione e l'interpretazione. MediAzioni, 29, 27-51.

Fortney, K. \& Gonder, J. (2015). A social networking site is not an open access repository. Retrieved from https://osc.universityofcalifornia.edu/2015/12/asocial-networking-site-is-not-an-open-access-repository

Franco Aixelá, J. (2001-2021). BITRA (Bibliography of Interpreting and Translation). Retrieved from https://doi.org/10.14198/bitra

Franco Aixelá, J. (2018). Gender and translation studies. A bibliometric approach. In J. T. Williams Camus, C. Gómez Castro, A. Assis Rosa, \& C. Camus Camus (Eds.), Translation and Gender. Discourse Strategies to Shape Gender (pp. 19-37). Santander: Universidad de Cantabria.

Franco Aixelá, J., Olalla-Soler, C., \& Rovira-Esteva, S. (2021). Open access in translation studies: A bibliometric overview of its distribution and development. Translation and Interpreting, 13(1), 1-23. https://doi.org/10.12807/ti.113201. 2021.a01

Freda, M. C., Kearney, M. H., Baggs, J. G., Broome, M. E., \& Dougherty, M. (2009). Peer reviewer training and editor support: Results from an international survey of nursing peer reviewers. Journal of Professional Nursing, 25(2), 101-108. https://doi.org/10.1016/j.profnurs.2008.08.007

Fuchs, C. \& Sandoval, M. (2013). The diamond model of open access publishing: Why policy makers, scholars, universities, libraries, labour unions and the publishing world need to take non-commercial, non-profit open access serious. TripleC, 11(2), 428-443. https://doi.org/10.31269/triplec.v11i2.502

Funamori, M. (2017). Open science and the academy: A theoretical discussion. Proceedings - 2017 6th IIAI International Congress on Advanced Applied Informatics, IIAI-AAI 2017, (1), 109-115. https://doi.org/10.1109/IIAIAAI.2017.19

Fyfe, A. (2015). Journals, learned societies and money: Philosophical Transactions, ca. 1750-1900. Notes and Records: The Royal Society Journal of the History of Science, 69(3), 277-299. https://doi.org/10.1098/rsnr.2015.0032

Fyfe, A. (2016). Journals and periodicals. In B. Lightman (Ed.), A companion to the history of science (pp. 387-399). Hoboken: Wiley Blackwell.

Gadd, E. (2020). Elsevier have endorsed the Leiden Manifesto: so what? The Bibliomagician. Retrived from https://thebibliomagician.wordpress.com/2020/09 /02/elsevier-have-endorsed-the-leiden-manifesto-so-what

Gambier, Y., Schaeffner, C., \& Meylaerts, R. (2019). Doctoral training in translation studies. Challenges and opportunities. In D. B. Sawyer, F. Austermühl, \& V. Enríquez Raído (Eds.), The evolving curriculum in interpreter and translator education: stakeholder perspectives and voices (pp. 99-116). Amsterdam: John Benjamins. https://doi.org/10.1075/ata.xix.05gam

Gile, D. (2013). Scientificity and theory in translation studies. In Y. Gambier \& L. van Doorslaer (Eds.), Handbook of translation studies. Volume 4 (pp. 148-155). Amsterdam: John Benjamins. https://doi.org/10.1075/hts.4.sci2

Godlee, F., Gale, C. R. \& Martyn, C. N. (1998). Effect on the quality of peer review of blinding reviewers and asking them to sign their reports. JAMA, 280(3), 237. https://doi.org/10.1001/jama.280.3.237

Göpferich, S. (2010). Data documentation and data accessibility in translation process research. Translator, 16(1), 93-124. https://doi.org/10.1080/13556509.2010.1079 9295

Gorraiz, J., Melero-Fuentes, D., Gumpenberger, C., \& Valderrama-Zurián, J.-C. (2016). Availability of digital object identifiers (DOIs) in Web of Science and Scopus. Journal of Informetrics, 10(1), 98-109. https://doi.org/10.1016/j.joi.2015 .11 .008

Gruber, T. (2014). Academic sell-out: how an obsession with metrics and rankings is damaging academia. Journal of Marketing for Higher Education, 24(2), 165-177. https://doi.org/10.1080/08841241.2014.970248

Gupta, B. M. \& Dhawan, S. M. (2019). Machine translation research. A scientometric assessment of global publications output during 2007-16. DESIDOC Journal of Library \& Information Technology, 39(1), 31-38. https://d oi.org/10.14429/djlit.39.1.13558

Harnad, S., Brody, T., Vallières, F., Carr, L., Hitchcock, S., Gingras, Y., ... Hilf, E. R. (2004). The access/impact problem and the green and gold roads to open access. Serials Review, 30(4), 310-314. https://doi.org/10.1016/j.serrev.2004.09.013 
Hicks, D., Wouters, P., Waltman, L., de Rijcke, S., \& Rafols, I. (2015). Bibliometrics: The Leiden manifesto for research metrics. Nature, 520(7548), 429-431. https://doi.org/10.1038/520429a

Houry, D., Green, S., \& Callaham, M. (2012). Does mentoring new peer reviewers improve review quality? A randomized trial. BMC Medical Education, 12(1), 83. https://doi.org/10.1186/1472-6920-12-83

IBM (2004). World Community Grid. Retrieved from https://www. worldcommunitygrid.org

Ioannidis, J. P. A. (2016). Anticipating consequences of sharing raw data and code and of awarding badges for sharing. Journal of Clinical Epidemiology, 70, 258-260. https://doi.org/10.1016/j.jclinepi.2015.04.015

Khoo, S. (2018). There is little evidence to suggest peer reviewer training programmes improve the quality of reviews. LSE Impact Blog. Retriev from https://blogs.lse.ac.uk/impactofsocialsciences/2018/05/23/there-is-littleevidence-to-suggest-peer-reviewer-training-programmes-improve-the-quality-ofreviews

Kidwell, M. C., Lazarević, L. B., Baranski, E., Hardwicke, T. E., Piechowski, S., Falkenberg, L. S., ... Nosek, B. A. (2016). Badges to acknowledge open practices: A simple, low-cost, effective method for increasing transparency. PLoS Biology, 14(5), 1-15. https://doi.org/10.1371/journal.pbio.1002456

Korpela, E., Werthimer, D., Anderson, D., Cobb, J., \& Leboisky, M. (2001). SETI@home-massively distributed computing for SETI. Computing in Science \& Engineering, 3(1), 78-83. https://doi.org/10.1109/5992.895191

Kraker, P., Leony, D., Reinhardt, W., Gü, N. A. \& Beham, N. (2011). The case for an open science in technology enhanced learning. International Jou rnal of Technology Enhanced Learning, 3(6), 643. https://doi.org/10.1504/IJTEL .2011 .045454

Lara, K. (2015). The library's role in the management and funding of open access publishing. Learned Publishing, 28(1), 4-8. https://doi.org/10.1087/20150102

Larivière, V., \& Sugimoto, C. R. (2019). The journal impact factor: A brief history, critique, and discussion of adverse effects. In W. Glänzel, H. F. Moed, U. Schmoch, \& M. Thelwall (Eds.), Springer handbook of science and technology indicators (pp. 3-24). Cham, Switzerland: Springer. https://doi.org/10.1007/9783-030-02511-3 1

Leavitt, K. (2013). Publication bias might make us untrustworthy, but the solutions may be worse. Industrial and Organizational Psychology, 6(3), 290-295. https://doi.org/10.1111/iops.12052

Liu, M. (2011). Methodology in interpreting studies: A methodological review of evidence-based research. In N. Brenda \& L. A. Swabey (Eds.), Advances in interpreting research. Inquiry in action (pp. 85-120). Amsterdam: John Benjamins. https://doi.org/10.1075/btl.99.08liu

Matheka, D., Nderitu, J., Mutonga, D., Otiti, M., Siegel, K., \& Demaio, A. (2014). Open access: academic publishing and its implications for knowledge equity in Kenya. Globalization and Health, 10(1), 26. https://doi.org/10.1186/1744-8603-10-26

Mellinger, C. D. (2020). Core research questions and methods. In E. Angelone, M. Ehrensberger-Dow, \& G. Massey (Eds.), The Bloomsbury companion to language industry studies (pp. 15-36). London: Bloomsbury. http://dx.doi.org/10.5040/ 9781350024960.0006

Mellinger, C. D., \& Baer, B. J. (2021). Research ethics in translation and interpreting studies. In K. Koshkinen \& N. K. Pokorn (Eds.), The Routledge handbook of translation and ethics (pp. 365-380). London: Routledge.

Mellinger, C. D., \& Hanson, T. A. (2017). Quantitative research methods in translation and interpreting studies. London: Routledge.

Mellinger, C. D., \& Hanson, T. A. (2019). Meta-analyses of simultaneous interpreting and working memory. Interpreting, 21(2), 165-195. https://doi.org/10.1075/intp. 00026.mel

Mellinger, C. D., \& Hanson, T. A. (2020). Meta-analysis and replication in interpreting studies. Interpreting, 22(1), 140-149. https://doi.org/10.1075/intp.00037.mel

Miguel, E., Camerer, C., Casey, K., Cohen, J., Esterling, K. M., Gerber, A., ... Van Der Laan, M. (2014). Promoting transparency in social science research. Science, 343(6166), 30-31. https://doi.org/10.1126/science.1245317

Moher, D., Bouter, L., Kleinert, S., Glasziou, P., Sham, M. H., Barbour, V., Coriat, A.M., Foeger, N., \& Dirnagl, U. (2020). The Hong Kong principles for assessing 
researchers: Fostering research integrity. PLOS Biology, 18(7), e3000737. https://doi.org/10.1371/journal.pbio.3000737

Momeni, F., Mayr, P., Fraser, N., \& Peters, I. (2021). What happens when a journal converts to open access? A bibliometric analysis. Retrived from http://arxiv.org/abs/2103.14522

Morrison, H. (2018). Global OA APCs (APC) 2010-2017: Major trends. In 22nd International Conference on Electronic Publishing. OpenEdition Press. https://doi.org/10.4000/proceedings.elpub.2018.16

Moser-Mercer, B. (1994). Paradigms gained or the art of productive disagreement. In S. Lambert \& B. Moser-Mercer (Eds.), Bridging the gap. Empirical research in simultaneous interpreting (pp. 17-23). Amsterdam: John Benjamins. https://doi.org/10.1075/btl.3.03mos

Muñoz Martín, R. (2014). A blurred snapshot of advances in translation process research. MonTI. Monografias de Traducción e Interpretación, Special issue 1, 49-84. https://doi.org/10.6035/MonTI.2014.ne1.1

National Academies of Sciences, Engineering, and Medicine (2018). Open science by design. Washington, D.C.: National Academies Press. https://doi.org/10.17226/ 25116

Nobes, A., \& Harris, S. (2019). Open access in low- and middle-income countries: Attitudes and experiences of researchers. Emerald Open Research, 1, 17. https://doi.org/10.35241/emeraldopenres.13325.1

Nosek, B. A. \& Bar-Anan, Y. (2012). Scientific utopia: I. Opening scientific communication. Psychological Inquiry, 23(3), 217-243. https://doi.org/10.1080/ 1047840X.2012.692215

Nosek, B. A., Ebersole, C. R., DeHaven, A. C. \& Mellor, D. T. (2018). The preregistration revolution. Proceedings of the National Academy of Sciences of the United States of America, 115(11), 2600-2606. https://doi.org/10.1073/pnas. 1708274114

Nosek, B. A., Spies, J. R. \& Motyl, M. (2012). Scientific utopia: II. Restructuring incentives and practices to promote truth over publishability. Pers pectives on Psychological Science, 7(6), 615-631. https://doi.org/10.1177/17456 91612459058

Olalla-Soler, C. (2020). Practices and attitudes toward replication in empirical translation and interpreting studies. Target, 32(1), 3-36. https://doi.org/10.1075/ target.18159.ola

Orero, P., Doherty, S., Kruger, J. L., Matamala, A., Pedersen, J., Perego, E., ... Szarkowska, A. (2018). Conducting experimental research in audiovisual translation (AVT): A position paper. Journal of Specialised Translation, 30, 105126.

Pan, R. K., Kaski, K., \& Fortunato, S. (2012). World citation and collaboration networks: uncovering the role of geography in science. Scientific Reports, 2(1), 902. https://doi.org/10.1038/srep00902

Phillips, M., \& Knoppers, B. M. (2019). Whose commons? Data protection as a legal limit of open science. Journal of Law, Medicine and Ethics, 47(1), 106-111. https://doi.org/10.1177/1073110519840489

Pöchhacker, F., \& Liu, M. (2021). Interpreting research in print. Interpreting, 23(1), 117. https://doi.org/10.1075/intp.00060.edi

Pontika, N., Knoth, P., Cancellieri, M., \& Pearce, S. (2015). Fostering open science to research using a taxonomy and an eLearning portal. Proceedings of the 15th International Conference on Knowledge Technologies and Data-Driven Business - i-KNOW'15, 21-22-Octo, 1-8. https://doi.org/10.1145/2809563.2809571

Ren, W., \& Huang, J. (2021). Mapping the structure of interpreting studies in China (1 996-2019) through co-word analysis. Perspectives. Studies in Translation Theory and Practice, (online first). https://doi.org/10.1080/0907676X.2021.1900881

RIN. (2008). Activities, costs and funding flows in the scholarly communications system in the UK. Retrieved from http://www.rin.ac.uk/our-work/communicating- anddisseminating-research/activities-costs-and-funding-flows- scholarly-commu

Ross-Hellauer, T. (2017). What is open peer review? A systematic review. F1000Research, 6(1), 588. https://doi.org/10.12688/f1000research.11369.1

Ross-Hellauer, T., \& Görögh, E. (2019). Guidelines for open peer review implementation. Research Integrity and Peer Review, 4(1), 4. https://doi.org/10.1186/s41073-019-0063-9

Ross-Hellauer, T., Deppe, A. \& Schmidt, B. (2017). Survey on open peer review: 
Attitudes and experience amongst editors, authors and reviewers. PLoS ONE, 12(12), 1-28. https://doi.org/10.1371/journal.pone.0189311

Rovira-Esteva, S., Franco Aixelá, J., \& Olalla-Soler, C. (2019). Citation patterns in translation studies: A format-dependent bibliometric analysis. Translation \& Interpreting, 11(1), 147-171. https://doi.org/10.12807/ti.111201.2019.a09

Rovira-Esteva, S., Franco Aixelá, J., \& Olalla-Soler, C. (2020). A bibliometric study of co-authorship in Translation Studies. Onomázein, 47, 158-194. https://doi.org/ 10.7764/onomazein.47.09

Russell, B. (2019). The future of open access business models: APCs are not the only way. The Scholarly Kitchen. The Blog of the Society of Scholarly Publishing. Retrived from https://scholarlykitchen.sspnet.org/2019/10/23/guest-post-thefuture-of-open-access-business-models-apcs-are-not-the-only-way

Sidler, M. (2014). Open science and the three cultures: Expanding open science to all domains of knowledge creation. In S. Bartling \& S. Friesike (Eds.), Opening Science (pp. 81-85). Cham, Switzerland: Springer. https://doi.org/10.1007/978-3319-00026-8

Sitek, D. \& Bertelmann, R. (2014). Open access: A state of the art. In S. Bartling \& S. Friesike (Eds.), Opening Science (pp. 139-153). Cham, Switzerland: Springer. https://doi.org/10.1007/978-3-319-00026-8

Smith, R. (2006). Peer review: a flawed process at the heart of science and journals. Journal of the Royal Society of Medicine, 99(4), 178-182. https://doi.org/ 10.1258/jrsm.99.4.178

Sugimoto, C. R., Work, S., Larivière, V., \& Haustein, S. (2017). Scholarly use of social media and altmetrics: A review of the literature. Journal of the Association for Information Science and Technology, 68(9), 2037-2062. https://doi.org/10.1002/ asi. 23833

Tahamtan, I., \& Bornmann, L. (2020). Altmetrics and societal impact measurements: Match or mismatch? A literature review. El profesional de la información, 29(1). https://doi.org/10.3145/epi.2020.ene.02

Tenopir, C., Dalton, E., Christian, L., Jones, M., McCabe, M., Smith, M., \& Fish, A. (2017). Imagining a gold open access future: Attitudes, behaviors, and funding scenarios among authors of academic scholarship. College \& Research Libraries, 78(6). https://doi.org/10.5860/crl.78.6.824

Thomas, F. P. \& Murphy, C. (2018). Shaping the future of science publishing: The evolution of metrics. The Journal of Spinal Cord Medicine, 41(2), 131-131. https://doi.org/10.1080/10790268.2018.1426289

Valdeón, R. A. (2019). Translation studies and the ethics of publishing. Perspectives, 27(5), 761-775. https://doi.org/10.1080/0907676X.2019.1631861

van Rooyen, S., Delamothe, T. \& Evans, S. J. W. (2010). Effect on peer review of telling reviewers that their signed reviews might be posted on the web: randomised controlled trial. BMJ, 341(16 Nov 2010), c5729-c5729. https://doi.org/10.1136/ bmj.c5729

Ware, M. (2008). Peer review: benefits, perceptions and alternatives. London: Publishing Research Consortium.

West, R. (2016). Data and statistical commands should be routinely disclosed in order to promote greater transparency and accountability in clinical and behavioral research. Journal of Clinical Epidemiology, 70, 254-255. https://doi.org/10.1016/ j.jclinepi.2015.06.015

Wierzbicka, A. (2011). Defining 'the humanities.' Culture \& Psychology, 17(1), 3146. https://doi.org/10.1177/1354067X10388841

Wolfram, D., Wang, P., Hembree, A., \& Park, H. (2020). Open peer review: promoting transparency in open science. Scientometrics, 125(2), 1033-1051. https://doi.org/10.1007/s11192-020-03488-4

Yang, S., Zheng, M., Yu, Y., \& Wolfram, D. (2021). Are altmetric.com scores effective for research impact evaluation in the social sciences and humanities? Journal of Informetrics, 15(1), 101120. https://doi.org/10.1016/j.joi.2020.101120

Zuckerman, H., \& Merton, R. K. (1971). Patterns of evaluation in science: Institutionalisation, structure and functions of the referee system. Minerva, 9(1), 66-100. https://doi.org/10.1007/BF01553188 
Appendix: Characteristics of TIS peer-reviewed journals (June 2020) Please see: https://doi.org/10.5281/zenodo.5090531 